\title{
Vialle Luiz Roberto (Ed), Jeffrey C. Wang, Claudio Lamartina (Guest Eds): AOSpine masters series vol 8
}

\author{
Thieme Verlag, New York, Stuttgart, Delhi, Rio de Janeiro, 2016, EUR (D) 109,99 EUR (A) 113.10 \\ CHF 126,00, ISBN: 978-1-62623-229-7
}

\section{Pierre Kehr ${ }^{1}$}

Received: 6 May 2018 / Accepted: 20 May 2018 / Published online: 4 June 2018

๑) Springer-Verlag France SAS, part of Springer Nature 2018

Volume 8 of this important AOSpine series devoted to the treatment of the spinal affections is dedicated to the low back pain. The "Evil of the Century" is studied by a panel of specialists international, North-American, but also European, in particular Italian and Swiss in great fame.

Following the example of the football games, the attribution of a red, yellow or blue paperboard is suggested in one of the first chapters. The supremacy of the clinical evaluation and the importance to indicate the precise clinical criteria to the radiologist, in order to avoid the redundant or useless examinations, are pointed out then. The sacro-iliac origin of the lumbago is a myth or a reality, another important question.

The chapters devoted to biology and the genetics of the intervertebral discs are studied, then follow neurological lumbago of origin, myopathies; lumbago of the children and teenagers; the pathology of the narrow lumbar canal and spine in elderly. The infections of the rachis, the treatments preserving and finally the place of the mini-invasive surgery constitute as many essential chapters.

For the pressed reader, to note that each chapter ends in a concise summary.

This Work is dedicated to all the doctors, orthopaedic surgeons, neurosurgeons, rehabilitation doctors and rheumatologists to justify the place of their speciality in the treatment of this pathology of the modern town man.

\section{Compliance with ethical standards}

Conflict of interest The author declare that he have no competing interests.
Pierre Kehr

Strasbourg, France 